\title{
Microtubule-Associated Protein 2 (MAP2) is Present in Astrocytes of the Optic Nerve but Absent from Astrocytes of the Optic Tract
}

\author{
Sozos Ch. Papasozomenos* and Lester I. Binder $\dagger$ \\ *Department of Pathology and Laboratory Medicine, The University of Texas Medical School, Houston, Texas \\ 77225, and †Department of Cell Biology and Anatomy, University of Alabama in Birmingham, Birmingham, \\ Alabama 35294
}

\begin{abstract}
Using the peroxidase-antiperoxidase staining technique at the light- and electron-microscope levels and two monoclonal antibodies against microtubule-associated protein 2 (MAP2), we found that astrocytes located at the periphery of the rat optic nerve were strongly stained, while those in the central region were very weakly stained. MAP2 immunoreactivity was present in astrocytes of the optic chiasm, but was absent from astrocytes in the optic tract. Inside astrocytes, MAP2 immunoreactivity was excluded from bundles of glial filaments. Treatment of animals with $\beta, \beta^{\prime}$-iminodipropionitrile (IDPN), which caused axonal atrophy, enhanced the staining intensity of all optic nerve astrocytes. Axons and oligodendrocytes remained unstained. Using PAGE and Western immunoblots, we found that extracts from bovine optic nerve contained MAP2. Astrocytes in any other region of the nervous system were negative for MAP2 immunoreactivity, except of the pituicytes and the astrocytes of the fimbria of hippocampus. The optic nerve, neurohypophysis, and hippocampal fimbria are white matter tracts that travel unsupported and free of surrounding nervous tissue. These findings suggest that MAP2 is expressed in astrocytes that are under excessive mechanical stress and further indicate that MAP2 may function as a cytoskeletal rigidifying agent in certain cells.
\end{abstract}

Microtubule-associated protein 2 (MAP2) is a heat-stable, highmolecular-weight phosphoprotein $\left(M_{\mathrm{r}} \sim 300,000\right)$ that maintains a constant stoichiometry to tubulin (Kim et al., 1979; Sloboda et al., 1975) during repetitive cycles of temperaturedependent assembly and disassembly of microtubules. It is the most abundant neuronal microtubule-associated protein but is not exclusively restricted to neurons (Izant and McIntosh, 1980; Kuznetsov et al., 1980; Sloboda and Dickersin, 1980; Valdivia et al., 1982; Weatherbee et al., 1982). In neurons, MAP2 is highly concentrated in dendrites and cell bodies (Matus et al., 1981; Papasozomenos et al., 1985). However, contrary to the prevailing belief that MAP2 is absent from all axons (Matus et al., 1981), we have recently shown that certain axons, especially spinal motor and other peripheral axons, contain significant amounts of MAP2 (Papasozomenos et al., 1982, 1985).

We and other investigators have previously demonstrated that all types of glial cells, including astrocytes, oligodendrocytes, ependymal cells, Schwann and satellite cells, and all types of mesenchymal cells in nervous tissue contain no immuno-

\footnotetext{
Received Sept. 18, 1985; revised Dec. 2, 1985; accepted Dec. 5, 1985.
}

We thank Dr. L. F. Eng for his gift of the antiserum against GFA protein, and Dr. R. P. Skoff for providing us with a preprint of his review article on the optic nerve astrocytes. We also thank Mrs. Jackie Sanders Fagan and Mrs. Ann Rose for typing the manuscript. This work was supported by NIH Grant NS22453 to S.C.P. and by NSF Grant DCB 8418264 to L.I.B.

Correspondence should be addressed to Dr. Papasozomenos, Department of Pathology and Laboratory Medicine, The University of Texas Medical School, P.O. Box 20708, Houston, TX 77225.

Copyright (C) 1986 Society for Neuroscience $0270-6474 / 86 / 061748-09 \$ 02.00 / 0$ detectable amounts of MAP2. Using light- and electron-microscopic immunostaining of rat optic nerve, chiasm, and tract and Western immunoblotting of extracts from bovine optic nerve, we report here that MAP2 is present in optic nerve astrocytes. In addition, while MAP2 immunoreactivity was detected in astrocytes of the optic chiasm, it is absent from astrocytes of the optic tract.

\section{Materials and Methods}

\section{Immunohistochemistry}

Fifteen male Sprague-Dawley rats weighting 250-350 gm were used. Under Nembutal anesthesia, the animals were perfused transcardially with a brief wash of PBS followed by $800 \mathrm{ml}$ of a mixture of $4 \%$ paraformaldehyde and $0.25 \%$ glutaraldehyde in $120 \mathrm{~mm}$ sodium potassium phosphate buffer $(\mathrm{pH} 7.4)$ at $37^{\circ} \mathrm{C}$. Immediately following perfusion,

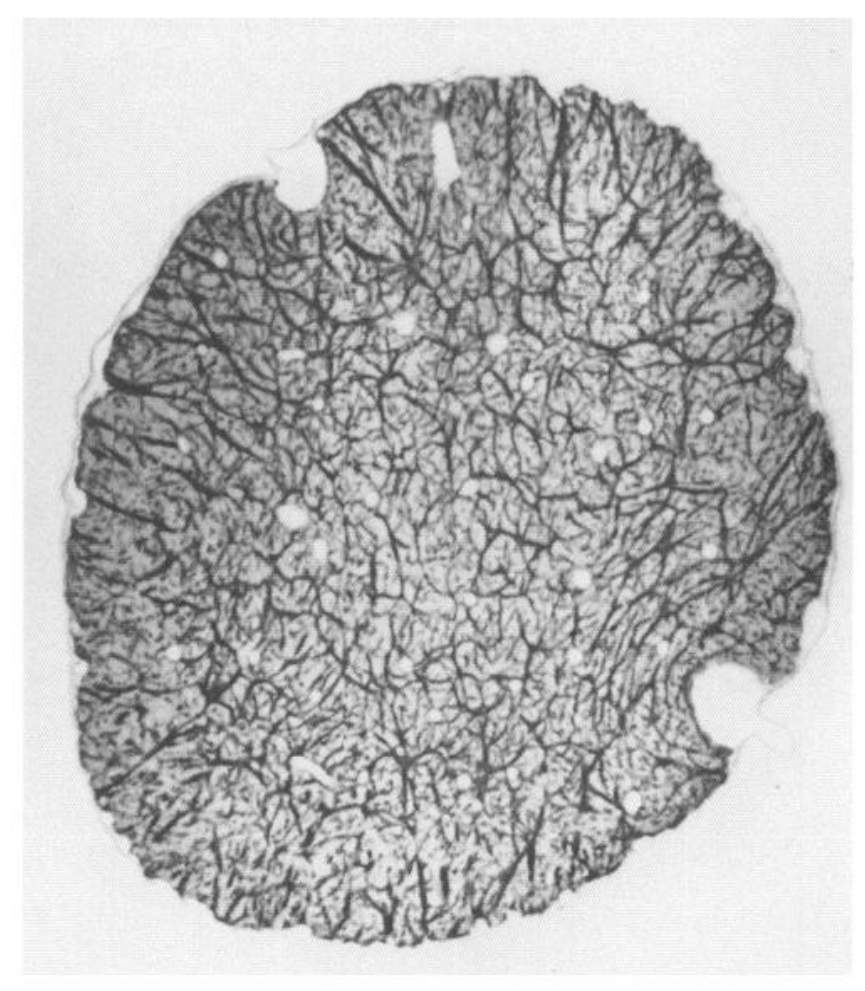

Figure 1. Epon-embedded, 2- $\mu$ m-thick cross section of the intracranial portion of rat optic nerve immunostained with the antiserum against GFA protein, diluted 1:1000. Note the intense staining of astrocytes, the rather radial disposition of primary astrocytic processes at the periphery, and the stellar shape of centrally located astrocytes. Multiple dark dots, Cross sections of longitudinally oriented processes. $\times 185$. 

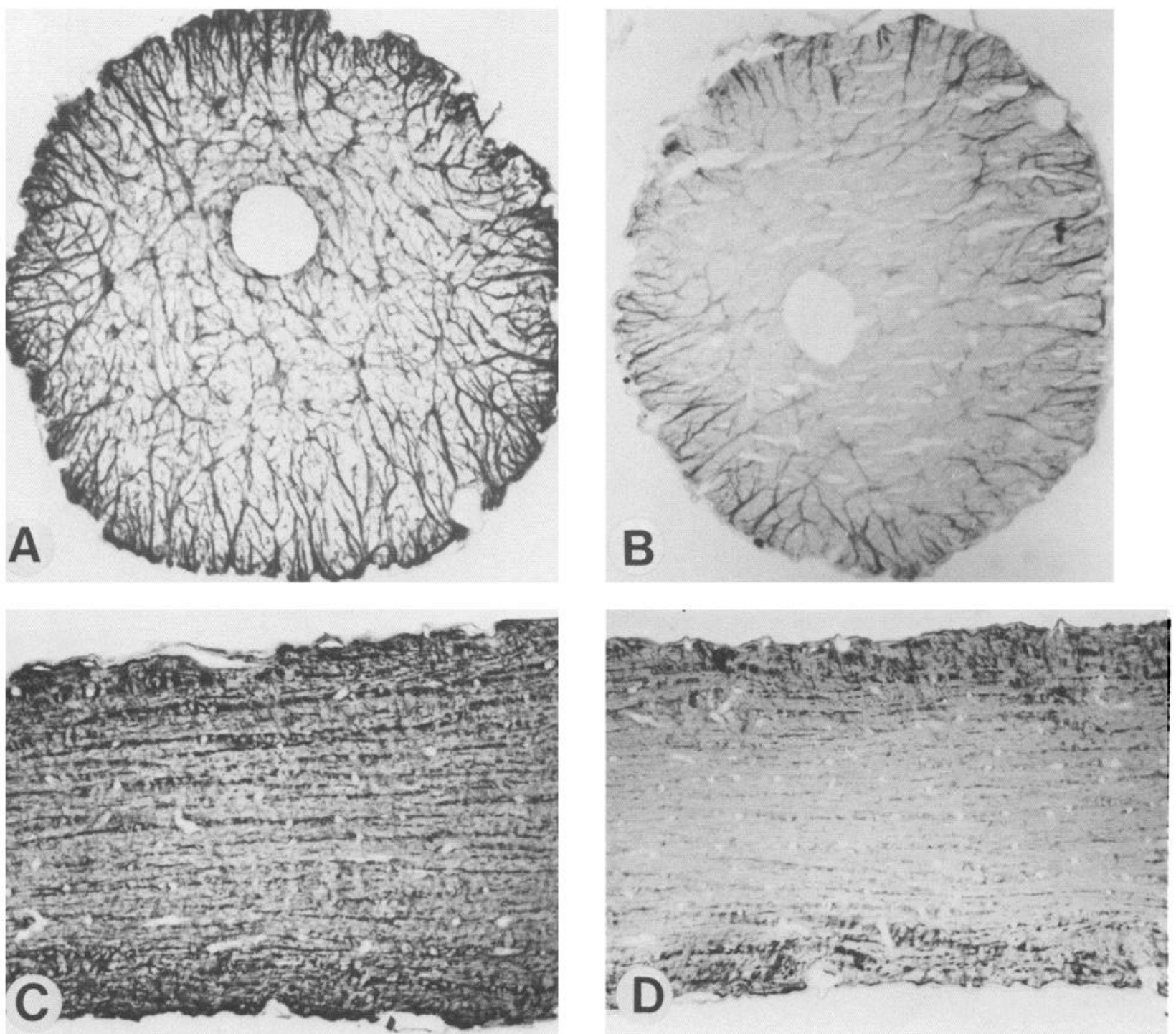

Figure 2. Adjacent, paraffin-embedded cross sections of the intraorbital $(A, B)$ and longitudinal $(C, D)$ sections of the intracranial portions of the rat optic nerve, reacted with GFA protein antiserum, diluted $1: 1000(A, C)$, and AP9, $0.74 \mu \mathrm{g} / \mathrm{ml},(B, D)$. The astrocytes are intensely stained with the GFA protein antiserum. While the astrocytes located at the periphery show strong MAP2 immunoreactivity, those located in the central region are only very weakly stained. Note that the astrocyte cell bodies are aligned in longitudinal rows and the astrocytic processes have a multidirectional distribution. $A, \times 220 ; B, \times 240 ; C, \times 145 ; D, \times 140$.

the intracranial portion of both optic nerves of all animals was removed. In several experiments, the intraorbital portion of both optic nerves and coronal sections of the entire brain at the levels of optic chiasm and optic tract and fimbria of hippocampus were also taken. Horizontal sections of the pituitary, which included the neurohypophysis at various levels, were also taken from a few animals. In addition, the optic nerves of another eight Sprague-Dawley rats treated with $\beta, \beta^{\prime}$-iminodipropionitrile (IDPN) as previously described (Papasozomenos et al., 1980, 1985 ) were sampled. Tissue samples were then fixed in $4 \%$ paraformaldehyde ( $\mathrm{pH} \mathrm{7.4)} \mathrm{at} 4^{\circ} \mathrm{C}$ for $1 \mathrm{hr}$ prior to dehydration and embedding in paraffin, Epon, and polyethylene glycol (PEG) for light-microscopic immunostaining. Alternatively, tissue samples were fixed in $4 \%$ paraformaldehyde $\left(\mathrm{pH} \mathrm{7.4)}\right.$ at $4{ }^{\circ} \mathrm{C}$ overnight and cut with a Vibratome for light- and electron-microscopic immunostaining. For immunostaining, the peroxidase-antiperoxidase technique was used, as has previously been described in detail (Papasozomenos et al., 1985). The production, characterization, and specificity of the anti-MAP2 monoclonal antibodies, designated AP9 and AP13, have been previously described (Binder et al., 1984; Caceres et al., 1984; Papasozomenos et al., 1985). The antiserum against glial fibrillary acidic (GFA) protein of bovine spinal cord was a gift from Dr. L. F. Eng, and its specificity has been repeatedly tested.

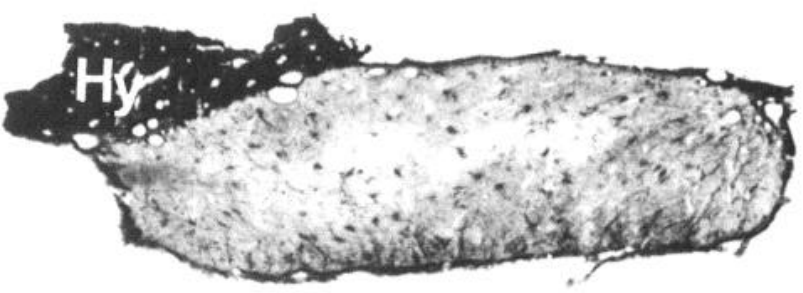

Figure 3. PEG-embedded, $10-\mu \mathrm{m}$-thick cross section of optic chiasm immunostained with AP13 $(0.78 \mu \mathrm{g} / \mathrm{ml})$. Astrocytes are intensely stained. Note the rather vertical orientation of astrocytic processes at the ventral one-fourth of optic chiasm. $\times 100$. 


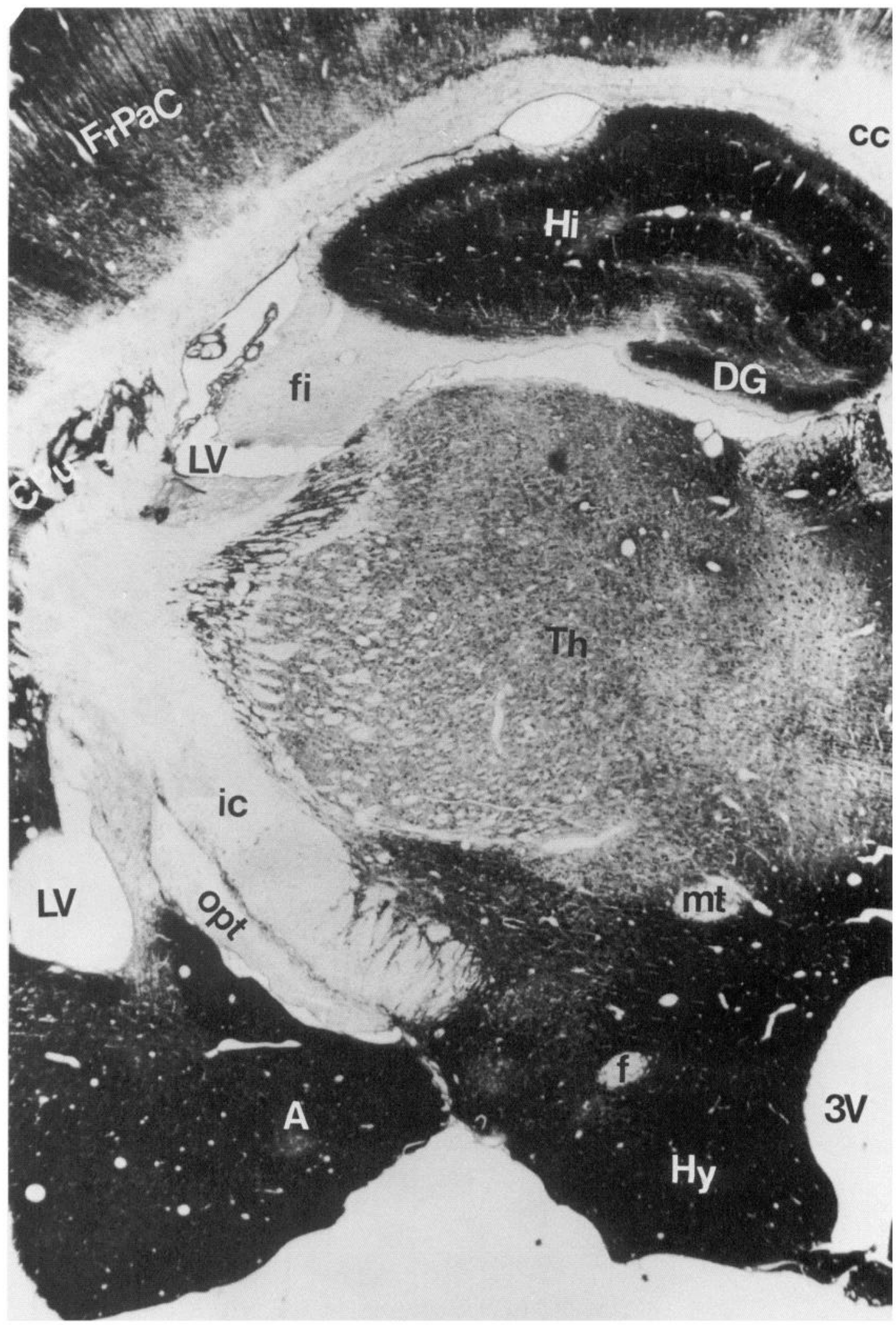

Figure 4. PEG-embedded, $10-\mu$ m-thick coronal section at the level of optic tract (opt) and fimbria ( $f$ ) of hippocampus immunostained with AP13 $(0.78 \mu \mathrm{g} / \mathrm{ml})$. No staining is present in the optic tract. Immunoreactive astrocytes in the fimbria of hippocampus can be better appreciated in Figure $8 A$. Note also the marked variability in staining intensity among different brain regions. Intensely stained regions: $A$, amygdala; $H y$, hypothalamus, $\mathrm{Hi}$, hippocampus; $\mathrm{DG}$, dendrate gyrus; $\mathrm{FrPaC}$, frontoparietal cortex; $C \mathrm{Pu}$, caudate putamen. Region with intermediate staining intensity: $\mathrm{Th}$, thalamus. Unstained regions: $c c$, corpus collosum; $i c$, internal capsule; $f$, fornix; $m t$, mammillothalamic tract. $3 V$, Third ventricle; $L V$, lateral ventricle. $\times 32$. 


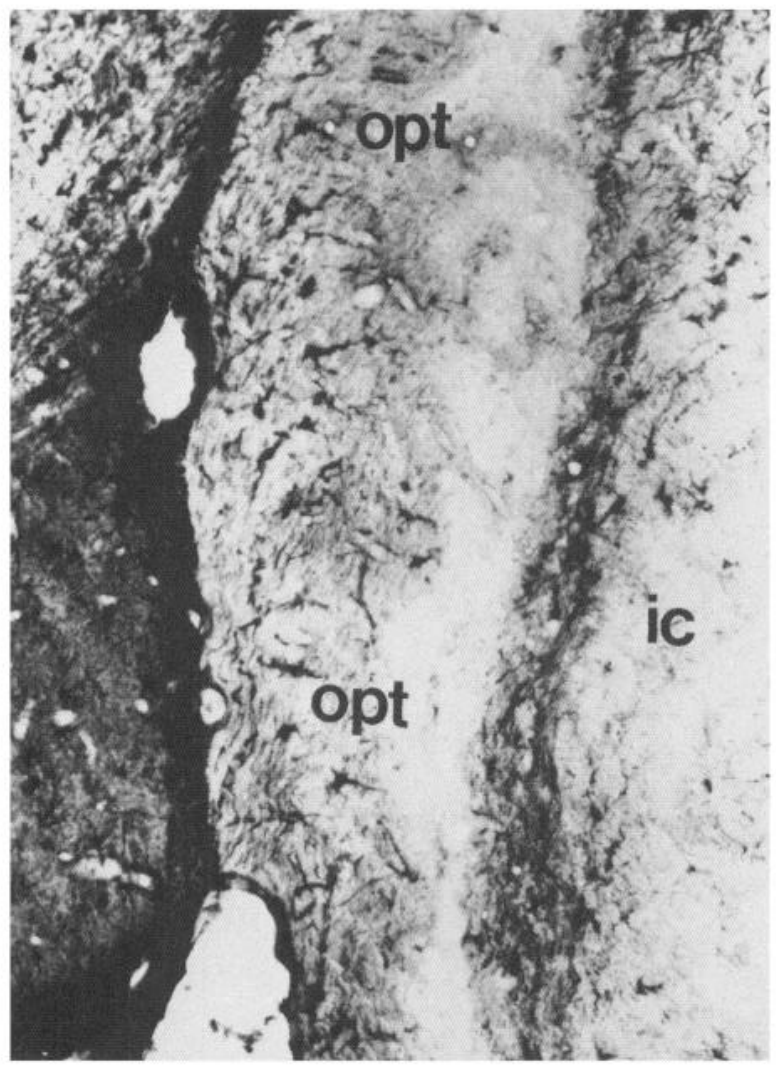

Figure 5. PEG-embedded, 10- $\mu$ m-thick coronal section immunostained with GFA protein antiserum, diluted 1:1000. At this level, intensely stained astrocytes appear to be concentrated at the lateral half of the optic tract $(o p t)$. ic, Internal capsule. $\times 145$.

\section{Electrophoretic and immunoblotting procedures}

Soluble extracts of bovine optic nerve were made by homogenizing at a ratio of $1 \mathrm{gm}$ tissue/ $1 \mathrm{ml}$ of buffer containing $100 \mathrm{~mm}$ PIPES, $2 \mathrm{~mm}$ EGTA, $1 \mathrm{mM} \mathrm{MgSO}_{4}, 0.1 \mathrm{~mm}$ GTP, pH 6.8, adjusted with $\mathrm{NaOH}$. The homogenate was centrifuged at $110,000 \times g$ for $1 \mathrm{hr}$ and the supernatant removed and prepared for electrophoresis. Samples were electrophoresed on 5-12.5\% linear polyacrylamide gradient gels prepared according to the method of Laemmli (1970). On completion of electrophoresis, the gels were either stained with Coomassie brilliant blue $\mathbf{R}$ or were transferred to nitrocellulose as described by Towbin et al. (1979). Blotted nitrocellulose sheets were blocked by gentle agitation in $5 \%$ nonfat dry milk (wt/vol) in $50 \mathrm{~mm}$ Tris- $\mathrm{HCl}, 0.2 \mathrm{~m}$ sodium chloride, $\mathrm{pH} 7.6$ (Tris-saline) for $45 \mathrm{~min}$ at room temperature (Johnson et al., 1984) and incubated overnight at $4^{\circ} \mathrm{C}$ in $80 \mu \mathrm{g} / \mathrm{ml}$ of AP9 or $400 \mu \mathrm{g} /$ $\mathrm{ml}$ of AP13. Following incubation with primary antibody, plots were washed and blocked again for $15 \mathrm{~min}$ in $5 \%$ nonfat dry milk and incubated with peroxidase-conjugated goat anti-mouse IgG (Hyclone, Provo, UT), diluted 1:5000, for $2-3 \mathrm{hr}$ at $4^{\circ} \mathrm{C}$. All the above dilutions and washings were made with Tris-saline. At this time, the blots were washed again 3-4 times with Tris-saline and placed in a substrate solution containing $0.075 \%$ (vol/vol) $\mathrm{H}_{2} \mathrm{O}_{2}, 0.04 \%$ (wt $/ \mathrm{vol}$ ) 3,3'-diaminobenzidine tetrahydrochloride and $10 \mathrm{~mm}$ imidazole, in $50 \mathrm{~mm}$ Tris- $\mathrm{HCl}, \mathrm{pH}$ 7.6. The reaction was stopped after sufficient color had developed (ca. 2-3 $\mathrm{min}$ ) by immersing the blot in deionized water. Following air-drying on filter paper, the immunoblots were photographed using a dark blue filter.

\section{Results}

Immunohistochemistry of rat optic nerve, chiasm, and tract

The intracranial portion of the optic nerve was studied in all animals, and in several rats the intraorbital portion, the optic chiasm, and tract were also examined.

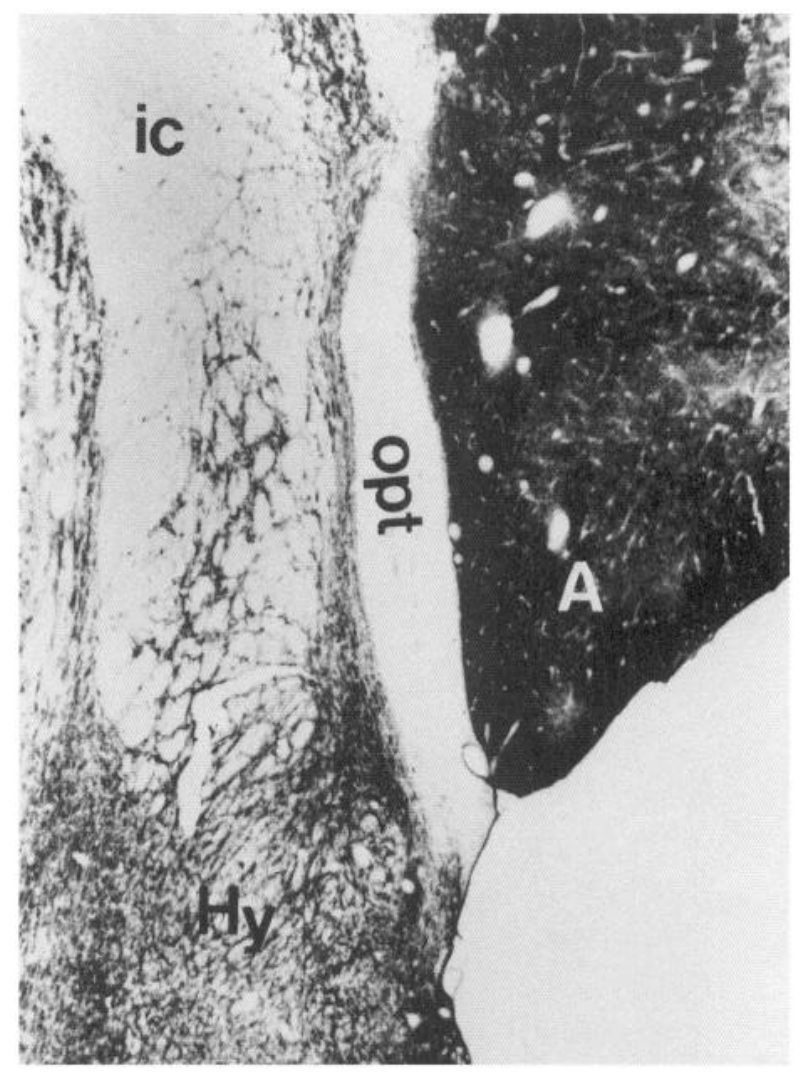

Figure 6. Vibratome, $30-\mu \mathrm{m}$-thick coronal section at the level of the optic tract (opt) reacted with AP13 $(0.78 \mu \mathrm{g} / \mathrm{ml})$. No MAP2 immunoreactivity is detectable in the optic tract. $A$, Amygdala; $H y$, hypothalamus; $i c$, internal capsule. $\times 35$.

\section{GFA immunoreactivity}

The antiserum to GFA protein intensely stained the astrocytes in cross and longitudinal sections of the optic nerve (Figs. 1 and 2, $A$ and $C$ ). In cross section, the overall distribution of astrocytic processes was multidirectional. Mostly elongated cells with prominent, intensely stained and radially arranged primary processes were located at the periphery of the optic nerve, while the astrocytes located at the central region had a more stellar shape and thinner processes (Figs. 1 and $2 A$ ). A barely perceptible gradient in staining intensity was present between the central and peripheral astrocytes, the latter being the most immunoreactive. Present among the radially or transversely oriented processes were multiple dots of intense immunoreactivity, representing cross sections of longitudinally oriented processes (Figs. 1 and $2 A$ ). In longitudinal sections, the astrocyte cell bodies were aligned in rows spanning the entire width of the optic nerve (Fig. 2C). Intensely stained astrocytes were also present in the optic chiasm and tract (Fig. 5).

\section{MAP2 immunoreactivity}

Both anti-MAP2 monoclonal antibodies, designated AP9 and AP13, produced identical results. At the light-microscopic level, rather strong MAP2 immunoreactivity was obtained in astrocytes located at the periphery of the optic nerve, while the centrally located astrocytes were very weakly stained (Figs. 2, $B$ and $D$, and $9 B$ ). The peripherally located, MAP2-positive astrocytes occupied a concentric area ending approximately at the midpoint of the radius of the optic nerve (Fig. $2 B$ ). This staining pattern of rather strong MAP2 immunoreactivity limited to the peripheral astrocytes was found along the entire length of the optic nerve (Fig. 2D). 


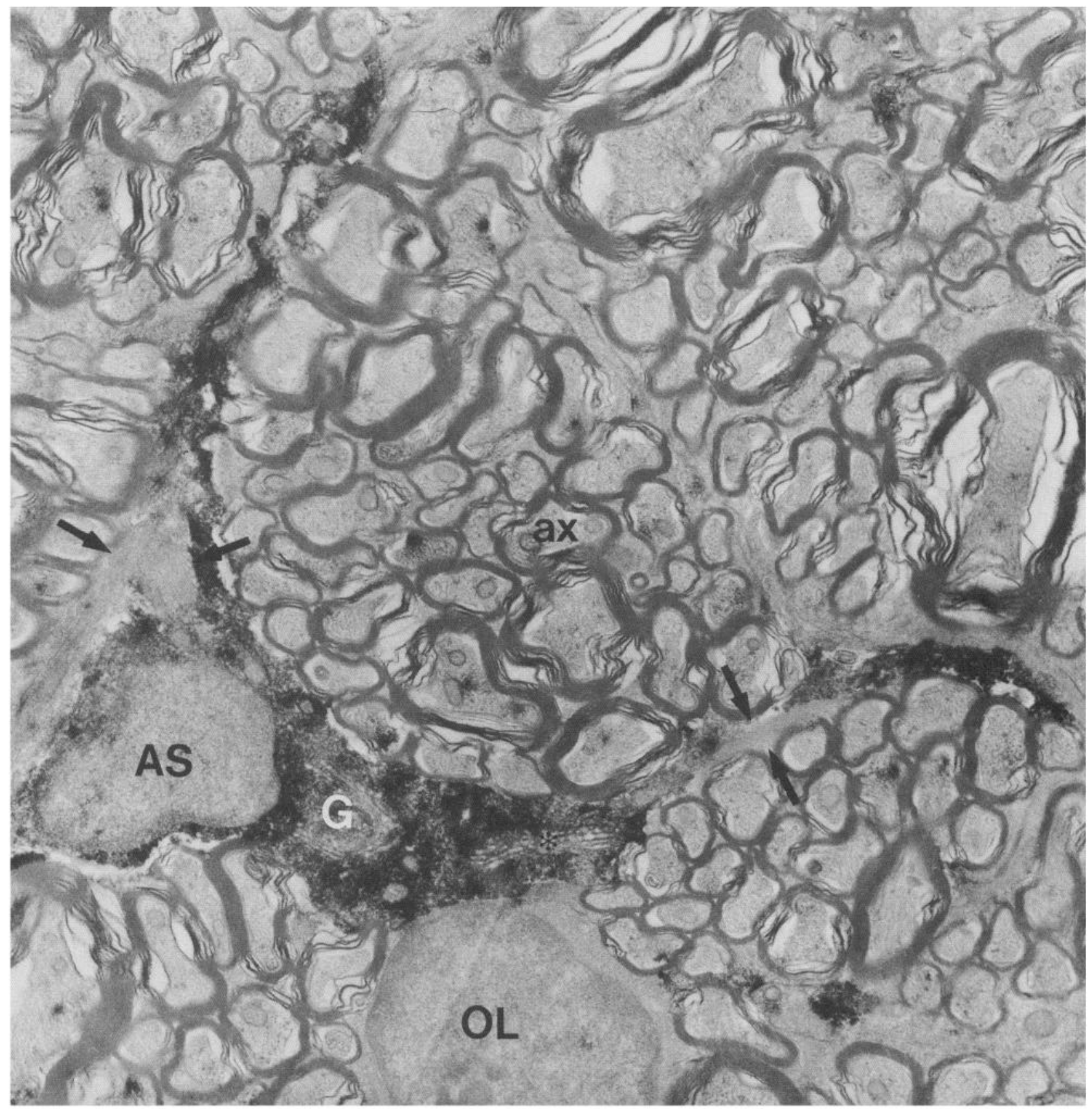

Figure 7. Electron micrograph of a Vibratome cross section of the intracranial portion of rat optic nerve immunostained with AP13 (0.78 $\mu$ g/ $\mathrm{ml})$. The cell body and two processes of an astrocyte $(A S)$ are intensely stained. The immunoreactive product is excluded from bundles of glial filaments (between arrows), the Golgi apparatus $(G)$, mitochondria, stacks of membranous organelles (asterisk), and the nucleus. An oligodendrocyte $(O L)$ and axons $(a x)$ remained unstained. $\times 14,000$.

In the optic chiasm, stellate astrocytes with strong immunoreactivity were present along the upper three-fourths of the chiasm, while in the lower fourth the strongly stained astrocytic processes had a vertical disposition (Fig. 3). By contrast, the astrocytes in the optic tract, along with oligodendrocytes and axons, remained unstained (Figs. 4 and 6).

Electron-microscopic immunocytochemistry performed on Vibratome sections showed intense MAP2 immunoreactivity in astrocyte cell bodies and their processes (Fig. 7). The staining appeared to be mostly diffuse with accentuation around mitochondria, which were negative, and occasional punctate localization, perhaps on microtubules. In the cell bodies, the Golgi apparatus and stacks of membranous profiles remained unstained. MAP2 immunoreactivity was excluded from bundles of glial filaments in the astrocytic cell bodies and processes. All axons, which were partitioned by astrocytic processes into fascicles, contained no MAP2 immunoreactivity. Oligodendrocytes were also negative (Fig. 7).

\section{MAP2 immunoreactivity in astrocytes of other sites}

The above findings demonstrating the presence of MAP2 in astrocytes of the optic nerve only, and the absence of MAP2 from optic tract and so many other sites of the CNS that have been examined (see below), prompted us to examine two other 

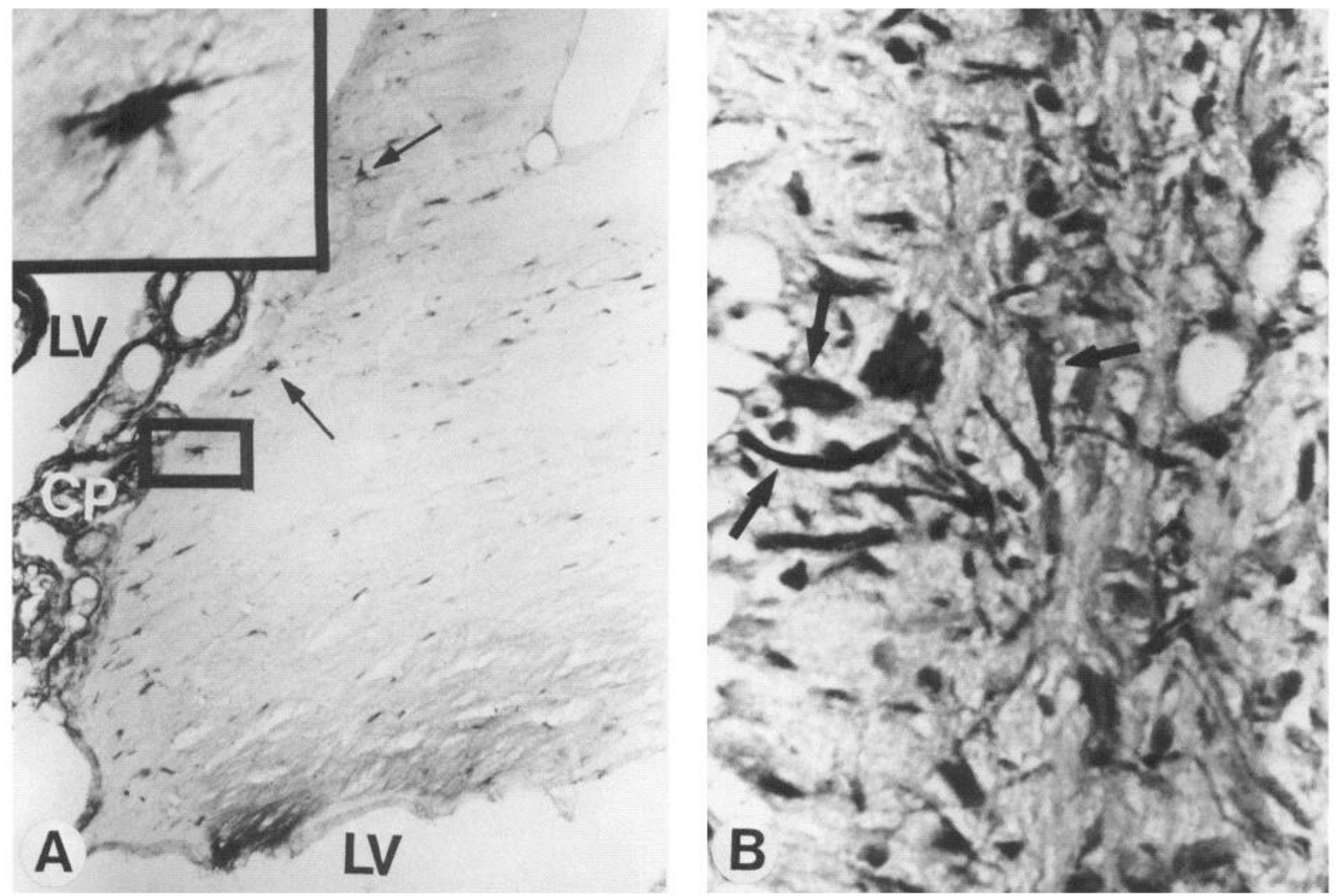

Figure 8. A, Fimbria of hippocampus from Figure 4 shown magnified. Several astrocytes are intensely stained (arrows). The astrocyte inside the boxed area is shown enlarged (inset). Darkening of choroid plexus $(C P)$ is nonspecific. $L V$, Lateral ventricle. $\times 145 ;$ inset, $\times 910 . B$, Paraffinembedded, 6- $\mu \mathrm{m}$-thick section of neurohypophysis reacted with AP9 $(0.74 \mu \mathrm{g} / \mathrm{ml})$. The cell body and processes of pituicytes are intensely stained (arrows). Nuclei, demonstrated by counterstaining with hematoxylin, remained unstained. The empty structures at the periphery belong to the intermediate lobe. $\times 575$.

white matter tracts with unsupported spatial dispositions similar to the optic nerve: the neurohypophysis, which contains unmyelinated axons and pituicytes, a modified form of astrocyte, and the intraventricular portion of the fimbria of hippocampus, which is composed of myelinated axons and glial cells. Not to our surprise, both pituicytes and astrocytes in the fimbria of hippocampus contained MAP2 immunoreactivity (Fig. 8, $A, B$ ).

In multiple experiments, virtually all other regions of the $\mathrm{CNS}$ were examined. These regions included coronal sections at various levels of cerebral cortex, white matter, and basal ganglia; sagittal and horizontal sections of cerebellar cortex, white matter, and deep nuclei; horizontal and sagittal sections of midbrain, pons, and medulla; and cross and longitudinal sections of spinal cord at the cervical, thoracic, and lumbosacral levels. No MAP2 immunoreactivity was found in the astrocytes at any of these sites other than those described above, although in areas with dense dendritic staining and small neuronal cell bodies, identification of astrocytes was not always possible. However, in sagittal sections of cerebellum, the easily identifiable long vertical palisades of Bergmann fibers (De Blas, 1984) were negative for MAP2 immunoreactivity.

\section{MAP2 immunoreactivity in astrocytes of optic nerve in IDPN-treated rats}

IDPN produced distal atrophy of rat optic nerve axons, as has been previously demonstrated in dogs (Parhad et al., 1982). Immunostaining of the optic nerve of IDPN-treated rats revealed strong MAP2 immunoreactivity not only in peripheral but in centrally located astrocytes, indicating an overall enhancement of staining intensity when compared with untreated rats (Fig. 9).

\section{Immunoblots of bovine optic nerve}

Immunoblots of extracts from bovine optic nerve, prepared as described in Materials and Methods, revealed a doublet of polypeptides (MAP2a and MAP2b), which on polyacrylamide gels comigrated with the MAP2 standard (Fig. 10). Both monoclonal antibodies to MAP2 that were used in the immunohistochemical studies reacted only with the MAP2 doublet. In this context, it is worth noting that staining with Coomassie blue revealed no polypeptides comigrating with the MAP2 standard. This finding underlines once more the higher sensitivity of immunoblotting techniques.

\section{Discussion}

Using immunohistochemistry at the light- and electron-microscopic levels and Western immunoblotting, we have shown that astrocytes located mostly at the periphery of the optic nerve were immunoreactive for MAP2, while astrocytes in the optic tract were negative. Thus, optic nerve astrocytes together with pituicytes, which are thought to be modified astrocytes, and astrocytes in the fimbria of hippocampus appear to be the only types of glial cells that have been found to be immunoreactive for MAP2. In addition, treatment with IDPN enhanced the staining intensity in all optic nerve astrocytes so that centrally located astrocytes became strongly positive. The optic nerve and tract axons and oligodendrocytes remained unstained.

Monoclonal antibodies are exquisitely specific probes that recognize discrete epitopes on proteins. If an epitope is present on a polypeptide other than the immunogen, false-positive immunostaining is possible. In fact, unexpected cross-reactivities with monoclonal antibodies have been reported (Nigg et al., 

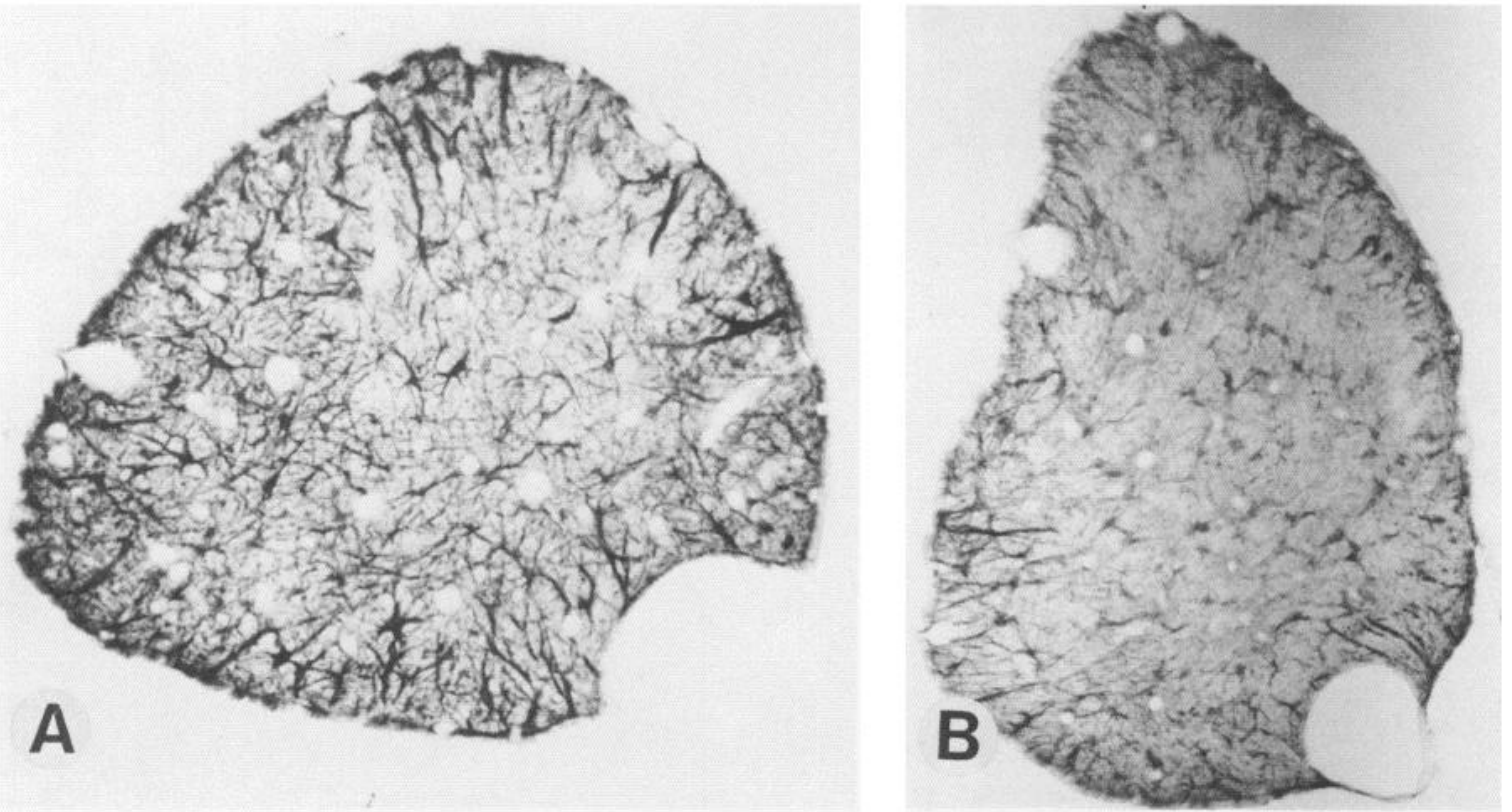

Figure 9. PEG-embedded, $10-\mu \mathrm{m}$-thick cross section of rat optic nerves immunostained with AP13 (0.78 $\mu \mathrm{g} / \mathrm{ml})$. $A$, Two weeks after IDPN administration; $B$, untreated. Following IDPN intoxication, there is a general enhancement of MAP2 immunoreactivity, so that the centrally located astrocytes are also strongly stained. Also compare $A$ with Figure $2, B$ and $D . A, \times 175 ; B, \times 140$.

1982; Pruss et al., 1981). However, our monoclonal antibodies have previously been shown to stain only the MAP2 doublet in immunoblots of extracts from spinal cord, cerebellum, and cerebrum (Binder et al., 1984; Caceres et al., 1984; Papasozomenos et al., 1985). Therefore, the combination of our immunocytochemical and immunobiochemical evidence leaves little doubt that optic nerve astrocytes contain MAP2.

The glial cells of the optic nerve of the rat are derived from primitive neuroepithelial cells of the optic stalk, a hollow tube that connects the diencephalic third ventricle with the optic cub (Kuwabara, 1975; Skoff et al., 1976a, b; Vaughn, 1969). In contrast to the rest of the neural tube, these matrix cells differentiate into astrocytes and oligodendrocytes only, and no neuronal differentiation takes place. It has been shown that the basal portion of this primitive neuroepithelium gives rise to astrocytes that form the glia limitans at the periphery of the optic nerve (Kuwabara, 1975). In addition, Miller and Raff (1984) showed that differentiation of these peripheral astrocytes takes place before birth. On the contrary, the centrally located astrocytes differentiate postnatally (Miller and Raff, 1984) and share with oligodendrocytes a common progenitor cell, which appears to depend on axons for its survival (David et al., 1984). That the optic nerve astrocytes constitute a heterogeneous population of cells has also been demonstrated with immunohistochemical techniques. Using antibodies against GFA protein and the monoclonal antibody $\mathrm{A}_{2} \mathrm{~B}_{5}$, which binds to several gangliosides (Kundu et al., 1983), Miller and Raff (1984) consider the peripherally located astrocytes as protoplasmic (weakly positive for GFA protein and negative for $\mathrm{A}_{2} \mathrm{~B}_{5}$ ) and the astrocytes in the central region of the optic nerve as fibrous (positive for GFA protein and $\mathrm{A}_{2} \mathrm{~B}_{5}$ ). While, with regard to GFA protein immunoreactivity, the above findings are at variance with ours and with previously published, similar studies (Dixon and Eng, 1981) that showed no significant difference in staining intensity between peripheral and central astrocytes, we did note centralperipheral heterogeneity of MAP2 immunoreactivity. Though the peripheral astrocytes were rather intensely stained, the astrocytes in the central region of the optic nerve showed very weak immunoreactivity.
The astrocytes of the optic nerve exhibit not only centralperipheral heterogeneity, as exemplified above, but also rostrocaudal heterogeneity. Along the entire length of the optic nerve dramatic changes in shape, distribution, and number of astrocytes takes place (Skoff et al., in press). This proximodistal astrocytic heterogeneity could probably account for the rather different distribution of MAP2-positive astrocytes in the optic chiasm.

The finding that among so many CNS sites only the astrocytes in the optic nerve, fimbria of hippocampus, and pituicytes, but not the optic tract, contained immunodetectable amounts of MAP2 is intriguing and might shed light on the in vivo function(s) of MAP2. All three of these white matter tracts travel unsupported by any surrounding brain tissue. While MAP2 is present in certain axons, perhaps mediating interactions between microtubules and neurofilaments (Papasozomenos et al., 1985), it is highly concentratd in dendrites and cell bodies, where the number of neurofilaments is relatively low. It is conceivable that in dendrites and cell bodies MAP2, as a component of the cytomatrix (Vallee et al., 1984), plays a primary role in the spatial organization of microtubules and other organelles and perhaps, as a crosslinker, lends mechanical support to the dendritic processes. The mammalian optic nerve is a long, thin extension of CNS that travels unsupported and free of any attached tissue between the cerebrum and the eye. It is in this way a specialized CNS pathway that is subjected to gravitational and other physical stresses without surrounding tissue support. The optic tract, on the other hand, while it constitutes a continuation of the optic nerve axons, is "embedded" in brain tissue, which provides mechanical support lacking in the optic nerve. It is then reasonable to suggest that the more abundant expression of MAP2 in a topographic subclass of optic nerve astrocytes occurs to counter the excessive mechanical stresses exerted on the unsupported nerve. This hypothesis is reinforced by the finding that pituicytes of the neurohypophysis and fimbria of the hippocampus, which are the only other two white matter tracts that travel unsupported, also express MAP2 immunoreactivity. If this is the case, then MAP2 may function by rigidifying microtubules and lending mechanical strength to the sur- 


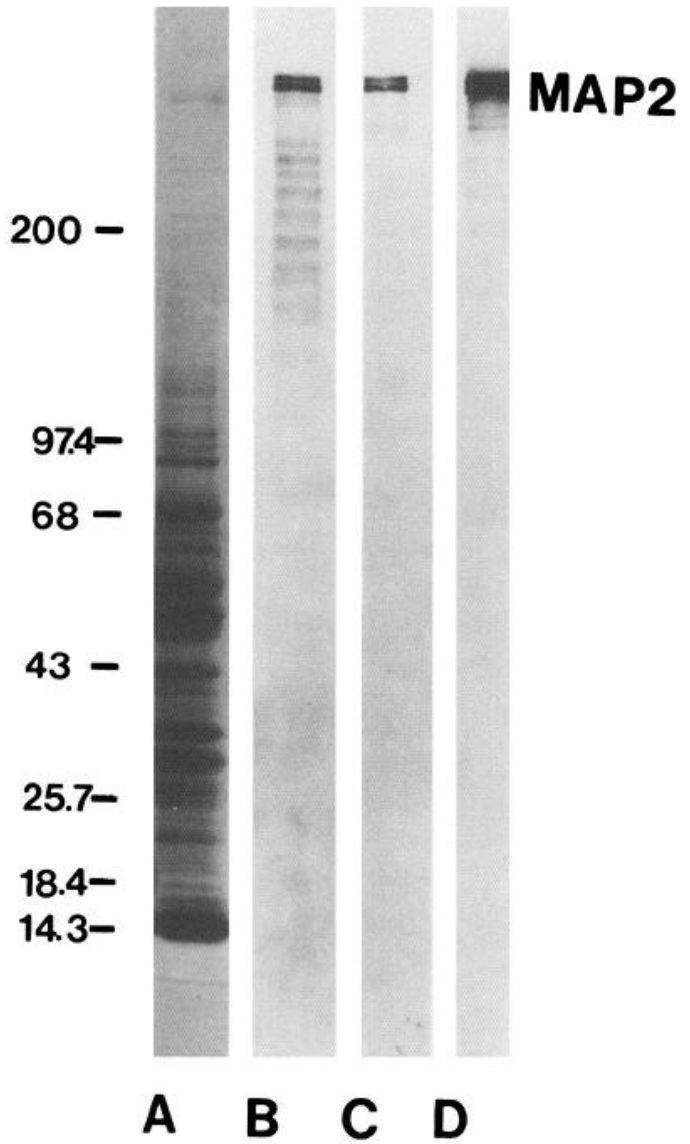

Figure 10. Immunoblot demonstrating the presence of MAP2 immunoreactivity in bovine optic nerve and the specificities of the MAP2 monoclonal antibodies used in our experiments. Soluble extracts of optic nerve, prepared according to the procedure outlined in Materials and Methods, were either electrophoresed and stained with Coomassie blue or transferred to nitrocellulose following electrophoresis. $A$, Coomassie blue stain of an optic nerve extract. $B$, Immunoblot of optic nerve extract probed with the anti-MAP2 monoclonal antibody AP9. $C$, Immunoblot as in $B$ but probed with AP13. Both of these antibodies are to different sites on the MAP2 molecule, as can be readily seen by comparing the different proteolytic fragment patterns beneath the MAP2 doublet illuminated by each antibody. $D$, MAP2 standard blotted and reacted with AP13. The numbers to the left in $A$ represent molecular weight $\left(\times 10^{-3}\right)$.

rounding cytoskeleton. The fact that only the astrocytes located at the periphery of the optic nerve contained significant amounts of MAP2-and that after IDPN-induced axonal atrophy and collapse, centrally located astrocytes were also rather intensely stained-suggests that the expression of MAP2 is a functional epiphenomenon rather than ontogenetically determined.

\section{References}

Binder, L. I., A. Frankfurter, H. Kim, A. Caceres, M. R. Payne, and L. I. Rebhun (1984) Heterogeneity of microtubule-associated protein 2 during rat brain development. Proc. Natl. Acad. Sci. USA 81: $5613-$ 5617.

Caceres, A., L. I. Binder, M. R. Payne, P. Bender, L. Rebhun, and O. Steward (1984) Differential subcellular localization of tubulin and the microtubule-associated protein MAP2 in brain tissue as revealed by immunocytochemistry with monoclonal hybridoma antibodies. J. Neurosci. 4: 394-410.

David, S., R. H. Miller, R. Patel, and M. C. Raff (1984) Effects of neonatal transection on glial cell development in the rat optic nerve: Evidence that oligodendrocyte cell lineage depends on axons for its survival. J. Neurocytol. 13: 961-974.
De Blas, A. L. (1984) Monoclonal antibodies to specific astroglial and neuronal antigens reveal the cytoarchitecture of the Bergmann glia fibers in the cerebellum. J. Neurosci. 4: 265-273.

Dixon, R. G., and L. F. Eng (1981) Glial fibrillary acidic protein in the optic nerve of the developing albino rat: An immunoperoxidase study of paraffin-embedded tissue. J. Comp. Neurol. 201: 15-24.

Izant, J. G., and J. R. McIntosh (1980) Microtubule-associated proteins: A monoclonal antibody to MAP2 binds to differentiated neurons. Proc. Natl. Acad. Sci. USA 77: 4741-4745.

Johnson, D. A., J. W. Gautsch, J. R. Sportsman, and J. H. Elder (1984) Improved technique utilizing non fat dry milk for analysis of proteins and nucleic acids transferred to nitrocellulose. Gene Anal. Technol. 1: 3-8.

Kim, H., L. I. Binder, and J. L. Rosenbaum (1979) The periodic association of MAP2 with brain microtubules in vitro. J. Cell Biol. 80: 266-276.

Kundu, S. K., M. A. Pleatman, W. A. Redwine, A. E. Boyd, and D. M. Marcus (1983) Binding of monoclonal antibody $\mathrm{A}_{2} \mathrm{~B}_{5}$ to gangliosides. Biochem. Biophys. Res. Commun. 116: 836-842.

Kuwabara, T. (1975) Development of the optic nerve of the rat. Invest. Opthalmol. 14: 732-745.

Kuznetsov, S. A., V. I. Rodionov, A. D. Bershadsky, V. I. Gelfand, and V. A. Rosenblat (1980) High molecular weight protein MAP2 promoting microtubule assembly in vitro is associated with microtubules in cells. Cell Biol. Int. Rep. 4: 1017-1024.

Laemmli, V. K. (1970) Cleavage of structural proteins during the assembly of the head of bacteriophage $T_{4}$. Nature 227: 680-685.

Matus, A., R. Bernhardt, and T. Hugh-Jones (1981) High molecular weight microtubule-associated proteins are preferentially associated with dendritic microtubules in brain. Proc. Natl. Acad. Sci. USA 78: 3010-3014.

Miller, R. H., and M. C. Raff (1984) Fibrous and protoplasmic astrocytes are biochemically and developmentally distinct. J. Neurosci. 4: 585-592.

Nigg, E. A., G. Walter, and S. J. Singer (1982) On the nature of crossreactions observed with antibodies directed to defined epitopes. Proc. Natl. Acad. Sci. USA 79: 5939-5943.

Papasozomenos, S. C., L. Autilio-Gambetti, and P. Gambetti (1981) Reorganization of axoplasmic organelles following $\beta, \beta^{\prime}$-iminodipropionitrile administration. J. Cell Biol. 91: 866-871.

Papasozomenos, S. C., L. I. Binder, P. Bender, and M. R. Payne (1982) A monoclonal antibody to microtubule-associated protein 2 (MAP2) localizes with neurofilaments in the $\beta, \beta^{\prime}$-iminodipropionitrile(IDPN) model. J. Cell Biol. (Abstr.) 95: 341a.

Papasozomenos, S.C., L. I. Binder, P. Bender, and M. R. Payne (1985) Microtubule-associated protein 2 within axons of spinal motor neurons: Associations with microtubules and neurofilaments in normal and $\beta, \beta^{\prime}$-iminodipropionitrile-treated axons. J. Cell Biol. 100: 7485 .

Parhad, I. M., J. W. Griffin, D. L. Price, A. W. Clark, L. C. Cork, N. R. Miller, and P. N. Hoffman (1982) Intoxication with $\beta, \beta^{\prime}$-iminodipropionitrile. A model of optic disc swelling. Lab. Invest. 46: 186-195.

Pruss, R. M., R. Mirsky, M. C. Raff, R. Thorpe, A. J. Dowding, and B. H. Anderton (1981) All classes of intermediate filaments share a common antigenic determinant defined by a monoclonal antibody. Cell 27: 4119-4228.

Skoff, R. P., D. L. Price, and A. Stocks (1976a) Electron microscopic autoradiographic studies of gliogenesis in rat optic nerve. I. Cell proliferation. J. Comp. Neurol. 169: 291-312.

Skoff, R. P., D. L. Price, and A. Stocks (1976b) Electron microscopic autoradiographic studies of gliogenesis in rat optic nerve. II. Time of origin. J. Comp. Neurol. 169: 313-333.

Skoff, R. P., P. E. Knapp, and W. P. Bartlett (in press) Astrocytic diversity in the optic nerve: A cytoarchitectural study. In Advances in Cellular Neurobiology, S. Fedoroff and A. Vernadakis, eds., Academic, New York.

Sloboda, R. D., and K. Dickersin (1980) Structure and composition of the cytoskeleton of nucleated erythrocytes. I. The presence of microtubule-associated protein 2 in the marginal band. J. Cell Biol. 87: 170-179.

Sloboda, R. D., S. A. Rudolph, J. L. Rosenbaum, and P. Greengard (1975) Cyclic AMP-dependent endogenous phosphorylation of a microtubule-associated protein. Proc. Natl. Acad. Sci. USA 72: 177181 . 
Towbin, H. T., T. Staehelin, and J. Gordon (1979) Electrophoretic transfer of proteins from polyacrylamide gels to nitrocellulose sheets: Procedure and some applications. Proc. Natl. Acad. Sci. USA 76: 4354-4356.

Valat, J., A. Privat, and J. Fulcrand (1983) Multiplication and differentiation of glial cells in the optic nerve of the postnatal rat. Anat. Embryol. 167: 335-346.

Valdivia, M. M., J. Avila, J. Coll, C. Colaco, and I. V. Sandoval (1982) Quantitation and characterization of the microtubule associated MAP2 in porcine tissues and isolation from porcine (PK15) and human (HeLa) cell lines. Biochem. Biophys. Res. Commun. 105: 1241-1249.
Vallee, R. B., G. S. Bloom, and W. E. Theurkauf (1984) Microtubuleassociated proteins: Subunits of the cytomatrix. J. Cell Biol. 99: 38s44s.

Vaughn, J. E. (1969) An electron microscopic analysis of gliogenesis in rat optic nerves. Z. Zellforsch. 94: 294-324.

Weatherbee, J. A., P. Sherline, R. N. Muscardo, J. G. Izant, R. B. Luftig and $R$. R. Weihing (1982) Microtubule-associated proteins of HeLa cells: Heat stability of the 200,000 molecular weight HeLA MAPs and detection of the presence of MAP2 in HeLa cells extracts and cycled microtubules. J. Cell Biol. 92: 155-163. 